\title{
The Effect of Surgical Bowel Manipulation and Anesthesia on Intestinal Glucose Absorption in Rats
}

\author{
Michael R. Uhing and Robert E. Kimura \\ Division of Neonatology, Department of Pediatrics, Rush Medical College, Rush-Presbyterian-St. Luke's Medical Center, \\ Chicago, Illinois 60612
}

\begin{abstract}
The effects of surgical bowel manipulation and anesthesia on intestinal glucose absorption were determined in chronically catheterized rats. Total and passive rates of glucose absorption were measured using 3-O-methyl-glucose (3OMG) and L-glucose, metabolically inert analogues of D-glucose. The rates of 30MG absorption immediately postoperative and $4 \mathrm{~h}$ later were 86 and $62 \%$ less than the absorption rate 6 d postoperative. The absorption rates of 30MG 1 and 2 d postoperative were not different from $6 \mathrm{~d}$ postoperative. Absorption of L-glucose was not altered by bowel manipulation and anesthesia. Even after correction for the increased resistance of the unstirred water layer (UWL) after bowel manipulation, the rates of total and active intestinal glucose absorption immediately postoperative were only 11 and $15 \%$ of predicted rates of absorption. In chronically catheterized rats, $>75 \%$ of luminal $30 \mathrm{MG}$ at a concentration of $400 \mathrm{mM}$ was absorbed by active transport. The $K_{\mathrm{m}}$ and $V_{\max }$ of 30MG active transport corrected for the resistance of the UWL were $11.3 \mathrm{mM}$ and $15.6 \mu \mathrm{moles} / \mathrm{min}$, respectively. We conclude that measurements of intestinal glucose absorption performed within $24 \mathrm{~h}$ of surgical bowel manipulation greatly underestimate active absorption even if corrections are made to account for the increased resistance of the UWL. (J. Clin. Invest. 1995. 95:2790-2798.) Key words: biological transport $\bullet$ permeability $\bullet$ unstirred water layer - methylglucosides $\cdot$ rat
\end{abstract}

\section{Introduction}

In an accompanying paper in this issue of The Journal, we measured portal venous-aortic concentration gradients of 3-Omethyl-glucose (3OMG) ${ }^{1}$ and L-glucose and found that $94 \%$ of luminal glucose is absorbed by active transport in chronically

Address correspondence to Division of Neonatology, Department of Pediatrics, Rush Medical College, Rush-Presbyterian-St. Luke's Medical Center, 1653 W. Congress Parkway, Chicago, IL 60612. Phone: 312-942-6640; FAX: 312-942-4370.

Received for publication 24 October 1994 and in revised form 17 January 1995.

1. Abbreviations used in this paper: 3OMG, 3-O-methyl-glucose; $\mathrm{C}_{1}$, concentration of substrate in bulk phase solution; $\mathrm{C}_{2}$, concentration of substrate at the microvillus interface; $J$, absorption rate; $K_{\mathrm{m}}$, MichaelisMenten constant; P, intestinal permeability; PEG, polyethylene glycol; $R$, resistance of the unstirred water layer; UWL, unstirred water layer.

J. Clin. Invest.

(C) The American Society for Clinical Investigation, Inc.

0021-9738/95/06/2790/09 $\$ 2.00$

Volume 95, June 1995, 2790-2798 catheterized rats (1). These results differ from the results of other studies that use methods in which measurements of glucose absorption are performed during or immediately after surgical bowel manipulation and show that passive absorption of glucose by the intestine begins to exceed active transport at luminal glucose concentrations as low as $35-60 \mathrm{mM}(2-5)$. We hypothesized that surgical bowel manipulation and anesthesia inhibit intestinal glucose absorption. Therefore, the discrepancy between our studies in chronically catheterized rats and previous studies using acute methods for studying intestinal absorption may be due to the influence of surgical bowel manipulation and anesthesia. In this paper, we provide evidence to support this hypothesis.

We developed a method for determining the rate of absorption of 3OMG and L-glucose, metabolically inert analogues of D-glucose, under physiologic conditions in chronically catheterized rats. 3OMG is actively transported by the same sodiumdependent cotransporter as D-glucose with a similar $V_{\max }$ and $K_{\mathrm{m}}(6,7)$. L-glucose is only passively absorbed with the same permeability coefficient as D-glucose $(6,8,9,10)$. Using our model, we are able to determine the intestinal absorption rate of $30 \mathrm{MG}$ and L-glucose by measuring the rate of increase in aortic blood concentrations of $\left[{ }^{3} \mathrm{H}\right]$ L-glucose or $\left[{ }^{3} \mathrm{H}\right] 30 \mathrm{MG}$ after their infusion into the duodenum and comparing them with the rate of increase of $\left[{ }^{14} \mathrm{C}\right] \mathrm{L}$-glucose or $\left[{ }^{14} \mathrm{C}\right] 3 \mathrm{OMG}$ simultaneously infused into portal vein at a constant rate. Because L-glucose and 3OMG are not metabolized or accumulated in the intestine, the rate of their appearance into the vascular system is equal to their absorption from the intestinal lumen $(9,11,12)$.

This method offers many advantages over previous methods. Intestinal function can be studied in unanesthetized, unrestrained animals in a nonfasting state without the influence of surgical bowel manipulation. Studies can be performed serially on the same animals at various times after surgical bowel manipulation and anesthesia. Because measurements of intestinal absorption are performed serially in the same animals, inter-animal variability is eliminated.

The purposes of this study were to determine (1) the effect of surgical bowel manipulation and anesthesia on intestinal glucose absorption by measuring 3-O-methyl-glucose (3OMG) and L-glucose absorption immediately postoperative and then serially over the next $6 \mathrm{~d},(2)$ whether changes in the resistance of the unstirred water layer (UWL) account for the changes in glucose absorption after surgical bowel manipulation or whether the changes in glucose absorption are due to changes in active transport, and (3) the rates of active and passive intestinal glucose absorption and the kinetics of intestinal glucose absorption without the influence of surgical bowel manipulation.

\section{Methods}

Chemicals. All nonradioactive chemicals and reagents were obtained from Sigma Chemical Co (St. Louis, MO). All radioactive isotopes 
were obtained from DuPont-New England Nuclear Research Products (Boston, MA).

Operative procedures. Male Sprague-Dawley rats weighing 250400 grams were obtained from Charles River Breeding Laboratories (Wilmington, MA). The rats were maintained under a 10:14 hour light:dark cycle. Water and chow (Agway Rat Mouse Hamster Chow 3000 ) were available ad libitum except where otherwise indicated.

Catheters were placed in the aorta, portal vein, and duodenum under sterile conditions as described in the accompanying paper (1). A schematic representation of the sites of catheter placement is shown in Fig. 1. To maintain catheter patency, the catheters were flushed daily with $0.35 \mathrm{ml}$ of $0.9 \% \mathrm{NaCl}$ containing $500 \mathrm{U} / \mathrm{ml}$ of heparin and $2.5 \mathrm{mg} / \mathrm{ml}$ of ampicillin.

Measurements of glucose absorption by the dual infusion method. Analogues of D-glucose that are not metabolized were used to measure intestinal glucose absorption. 3-O-methyl-D-glucose (3OMG) is actively transported at the brush border membrane by the major sodium-dependent transporter that transports D-glucose and at the basolateral membrane by the same facilitated diffusion carrier used by D-glucose (6, 13). Absorption of 3OMG reflects total glucose absorption (both active and passive). L-glucose is absorbed only passively $(6,8,9,10)$.

In this study, we shall measure the rate of intestinal absorption of $30 \mathrm{MG}$ and L-glucose by measuring their rate of appearance in the blood. In contrast, most previous studies of intestinal glucose absorption using techniques such as perfusion of an isolate intestinal loop or everted sleeves measure the rate of disappearance of glucose from the lumen or mucosal surface $(3,5,8,13-18)$. Because 3OMG and L-glucose are not metabolized or accumulated by the intestine, the rate of their appearance into the blood is equal to the rate of disappearance from the intestinal lumen $(9,11,12)$. In contrast, since D-glucose is metabolized by the intestine, the rate of appearance of D-glucose into the blood is less than is actually absorbed by the intestine $(12,19)$.

In preliminary experiments, we measured a constant rate of increase in the blood concentration of $\left[{ }^{3} \mathrm{H}\right] 3 \mathrm{OMG}$ and $\left[{ }^{3} \mathrm{H}\right]$ L-glucose for at least $5 \mathrm{~min}$ after a duodenal infusion of $100 \mathrm{mM} 30 \mathrm{MG}$ and $100 \mathrm{mM}$ L-glucose containing tracer amounts of their $\left[{ }^{3} \mathrm{H}\right]$ radiolabeled isotopes $\left(n=4, r^{2}=0.99 \pm 0.01\right.$ for both $)$. In addition, when $\left[{ }^{14} \mathrm{C}\right] 3 \mathrm{OMG}$ or $\left[{ }^{14} \mathrm{C}\right] \mathrm{L}$-glucose was constantly infused into the portal vein, there was a constant rate of increase in the blood concentration of $\left[{ }^{14} \mathrm{C}\right] 3 \mathrm{OMG}$ or $\left[{ }^{14} \mathrm{C}\right] \mathrm{L}$-glucose for at least $10 \mathrm{~min}\left(n=4, r^{2}=0.99 \pm 0.003\right.$ and $r^{2}=0.98 \pm 0.01$, respectively). Since $30 \mathrm{MG}$ and L-glucose are not metabolized, the rate of increase of $\left[{ }^{14} \mathrm{C}\right]$ and $\left[{ }^{3} \mathrm{H}\right] 3 \mathrm{OMG}$ and L-glucose is dependent of the rate of infusion of $\left[{ }^{14} \mathrm{C}\right] 3 \mathrm{OMG}$ and $\left[{ }^{14} \mathrm{C}\right] \mathrm{L}$-glucose into the portal vein and the rate of intestinal absorption of $\left[{ }^{3} \mathrm{H}\right]$ 3OMG and $\left[{ }^{3} \mathrm{H}\right] \mathrm{L}$-glucose. The constant rate of increase of blood $\left[{ }^{3} \mathrm{H}\right]$ 3OMG and $\left[{ }^{3} \mathrm{H}\right]$ L-glucose concentrations after a duodenal infusion indicates a constant rate of intestinal absorption during that time period. Since the rate of infusion of the $\left[{ }^{14} \mathrm{C}\right] 3 \mathrm{OMG}$ and $\left[{ }^{14} \mathrm{C}\right] \mathrm{L}$-glucose in the portal vein is known, we are able to calculate the rate of intestinal absorption of $\left[{ }^{3} \mathrm{H}\right] 3 \mathrm{OMG}$ and $\left[{ }^{3} \mathrm{H}\right]$ L-glucose by comparing the rates of increase of blood $\left[{ }^{3} \mathrm{H}\right]$ 3OMG and $\left[{ }^{3} \mathrm{H}\right]$ L-glucose to $\left[{ }^{14} \mathrm{C}\right] 3 \mathrm{OMG}$ and $\left[{ }^{14} \mathrm{C}\right] \mathrm{L}-$ glucose. Because the portal venous and duodenal infusions are simultaneous and proximal to the liver, the isotopes are influenced by the same first-pass effect, volume of distribution, and clearance rates.

Radziuk and Bondy described a similar method using dual infusion of radiolabeled tracers for measuring glucose absorption in humans (20). In their study, $\left[{ }^{14} \mathrm{C}\right] \mathrm{D}$-glucose was constantly infused into a peripheral vein. Simultaneously the $\left[{ }^{3} \mathrm{H}\right]$ D-glucose was given orally. The absorption of $\left[{ }^{3} \mathrm{H}\right]$ D-glucose was determined by comparing the increase of $\left[{ }^{3} \mathrm{H}\right] \mathrm{D}$-glucose and $\left[{ }^{14} \mathrm{C}\right] \mathrm{D}$-glucose in the peripheral blood.

In the present study, the method of Radziuk and Bondy was modified to eliminate some of their assumptions. 3OMG and L-glucose were used to avoid the need to make any assumption regarding the effects of metabolism. In addition, by constantly infusing tracer amounts of $\left[{ }^{14} \mathrm{C}\right] 3 \mathrm{OMG}$ and $\left[{ }^{14} \mathrm{C}\right] \mathrm{L}$-glucose directly into the portal vein instead of a peripheral vein, we have accounted for the effects of the liver on first-pass.

In this study, the dual infusion method for measuring intestinal

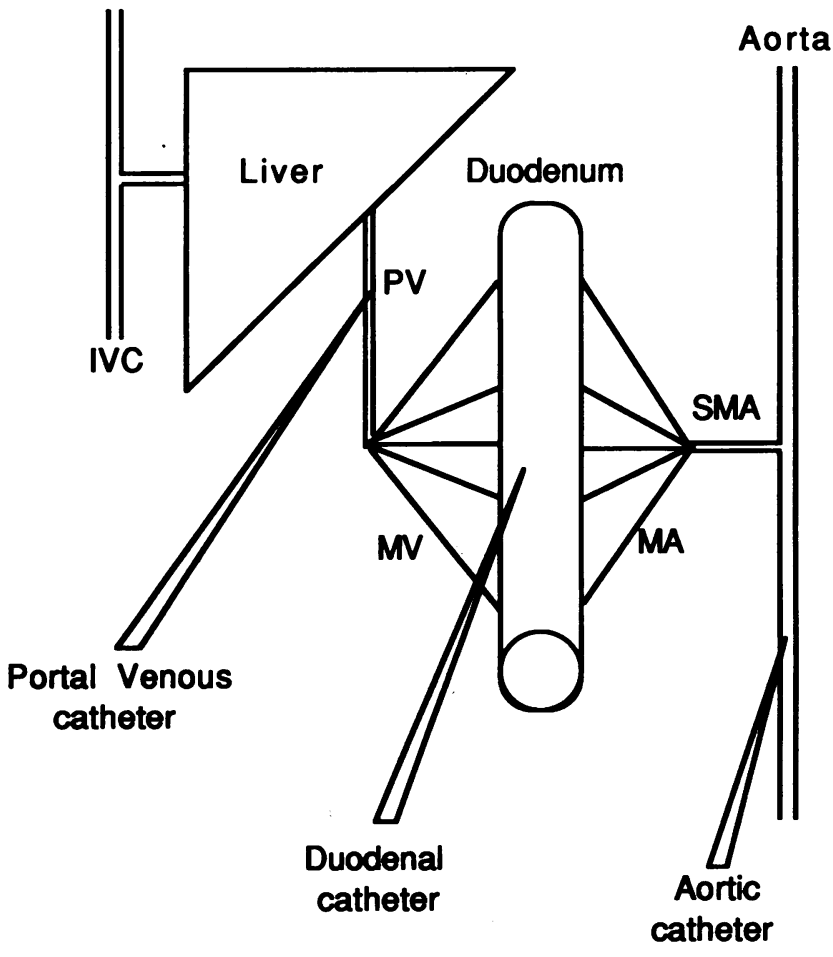

Figure 1. Schematic representation of catheter placement. Chronic catheters were placed in the portal vein, aorta, and duodenum in male Sprague-Dawley rats. The portal venous catheter and duodenal catheter were used for $\left[{ }^{14} \mathrm{C}\right]$ and $\left[{ }^{3} \mathrm{H}\right]$ radiolabeled infusions, respectively. The aortic catheter was used for blood sampling. IVC, inferior vena cava; $P V$, portal vein; $M V$, mesenteric veins; $M A$, mesenteric arteries; $S M A$, superior mesenteric artery.

glucose absorption was performed in the following manner (Fig. 1). Tracer amounts of $\left[{ }^{14} \mathrm{C}\right] 3$ - $O$-methyl-glucose (3OMG) or $\left[{ }^{14} \mathrm{C}\right] \mathrm{L}$-glucose $(0.4 \mu \mathrm{Ci} / \mathrm{ml})$ in $0.9 \% \mathrm{NaCl}$ were constantly infused into the portal vein at $0.2 \mathrm{ml} / \mathrm{min}$. Simultaneously, a $1.0 \mathrm{ml}$ bolus of 3OMG or Lglucose with tracer amounts of their $\left[{ }^{3} \mathrm{H}\right]$ isotopes $(2 \mu \mathrm{Ci} / \mathrm{ml})$ was infused into the duodenum. After approximately one minute, six serial aortic blood samples $(0.25 \mathrm{ml}$ each $)$ were drawn from the aortic catheter. The slope of $\left[{ }^{3} \mathrm{H}\right]$ and $\left[{ }^{14} \mathrm{C}\right]$ concentrations in the blood vs time was determined by linear regression analysis. The uptake of $\left[{ }^{3} \mathrm{H}\right]$ was determined as follows:

Uptake of $\left[{ }^{3} \mathrm{H}\right]$

$=\left(\right.$ slope of $\left.\left[{ }^{3} \mathrm{H}\right]\right)\left(\right.$ infusion rate of $\left.\left[{ }^{14} \mathrm{C}\right]\right) /\left(\right.$ slope of $\left.\left[{ }^{14} \mathrm{C}\right]\right)$

The uptake of $\left[{ }^{3} \mathrm{H}\right]$ was divided by the specific activity of $\left[{ }^{3} \mathrm{H}\right]$ in the infusate to determine the rate of uptake of the glucose analogue.

An example of one experiment is shown in Fig. 2. In this experiment, the absorption of 3OMG was measured after a $1 \mathrm{ml}$ duodenal infusion of $50 \mathrm{mM}$ 3OMG containing tracer amounts of $\left[{ }^{3} \mathrm{H}\right]$ 3OMG. Simultaneously, tracer amounts of $\left[{ }^{14} \mathrm{C}\right] 3 \mathrm{OMG}$ in $0.9 \% \mathrm{NaCl}$ were constantly infused into the portal vein at $0.2 \mathrm{ml} / \mathrm{min}$ or $184,324 \mathrm{cpm} / \mathrm{min}$. Aortic blood samples were drawn as described above and the concentrations of $\left[{ }^{3} \mathrm{H}\right]$ and $\left[{ }^{14} \mathrm{C}\right]$ determined. The slopes of blood $\left[{ }^{3} \mathrm{H}\right]$ and $\left[{ }^{14} \mathrm{C}\right]$ concentrations were $4,214 \mathrm{cpm} / \mathrm{ml}$ per min and $3314 \mathrm{cpm} / \mathrm{ml}$ per min, respectively. Using Eq. 1,

Uptake of $\left[{ }^{3} \mathrm{H}\right]$

$=(4,214 \mathrm{cpm} / \mathrm{ml}$ per $\min )(184,324 \mathrm{cpm} / \mathrm{min})$

$\div(3,314 \mathrm{cpm} / \mathrm{ml}$ per $\mathrm{min})$

$=234,426 \mathrm{cpm} / \mathrm{min}$ 


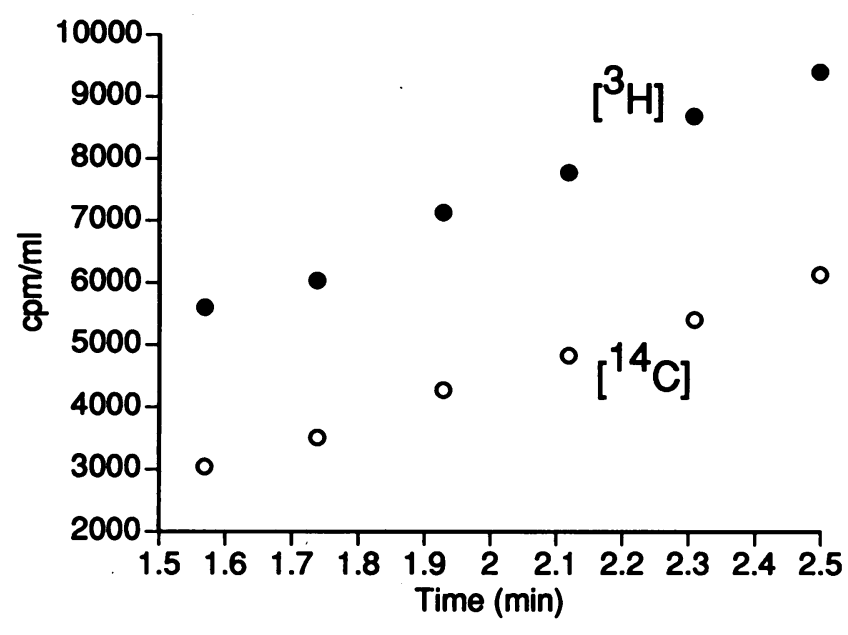

Figure 2. Concentrations of $\left[{ }^{3} \mathrm{H}\right]$ and $\left[{ }^{14} \mathrm{C}\right]$ vs. time during a dual infusion experiment. Tracer amounts of $\left[{ }^{14} \mathrm{C}\right] 3 \mathrm{OMG}$ were infused into the portal vein at $0.2 \mathrm{ml} / \mathrm{min}$ or $184324 \mathrm{cpm} / \mathrm{min}$. $1 \mathrm{ml}$ of $50 \mathrm{mM}$ $30 M G$ with tracer quantities of $\left[{ }^{3} \mathrm{H}\right] 3 \mathrm{OMG}$ was infused into the duodenum over $0.6 \mathrm{~min}$. Serial aortic blood samples were drawn from 1.5 to $2.5 \mathrm{~min}$ after the start of the duodenal infusion. The slopes of aortic blood concentrations of $\left[{ }^{3} \mathrm{H}\right](\bullet)$ and $\left[{ }^{14} \mathrm{C}\right](\mathrm{O})$ vs. time were 4214 $\mathrm{cpm} / \mathrm{ml} / \mathrm{min}\left(\mathrm{r}^{2}=0.99\right)$ and $3314 \mathrm{cpm} / \mathrm{ml}$ per $\min \left(\mathrm{r}^{2}=0.99\right)$, respectively. By comparing the slopes of $\left[{ }^{3} \mathrm{H}\right]$ and $\left[{ }^{14} \mathrm{C}\right]$ with the infusion rate of $\left[{ }^{14} \mathrm{C}\right]$, the uptake of $\left[{ }^{3} \mathrm{H}\right]$ was calculated as $234,426 \mathrm{cpm} / \mathrm{min}$. Since the specific activity of $\left[{ }^{3} \mathrm{H}\right]$ was $38.7 \mathrm{cpm} / \mathrm{nmole}$ of $3 \mathrm{OMG}$, the absorption of $30 \mathrm{MG}$ was $6.1 \mu \mathrm{mole} / \mathrm{min}$.

Since the specific activity of $\left[{ }^{3} \mathrm{H}\right]$ was $38.73 \mathrm{cpm} / \mathrm{nmole}$ of $3 \mathrm{OMG}$, the absorption of 3OMG can be calculated as follows:

Absorption of 3OMG

$=\left(\right.$ Uptake of $\left.\left[{ }^{3} \mathrm{H}\right]\right) /\left(\right.$ specific activity of $\left.\left[{ }^{3} \mathrm{H}\right]\right)$

$=(234,426 \mathrm{cpm} / \mathrm{min}) /(38.73 \mathrm{cpm} / \mathrm{nmole}$ of $3 \mathrm{OMG})$

$=6,052 \mathrm{nmoles} / \mathrm{min}=6.05 \mu \mathrm{moles} / \mathrm{min}$

Experimental design. The effect of surgical bowel manipulation on intestinal glucose absorption was determined by measuring the rates of absorption of 3OMG and L-glucose immediately postoperative and then $4 \mathrm{~h}, 1 \mathrm{~d}, 2 \mathrm{~d}$, and $6 \mathrm{~d}$ after catheter placement. The rats were separated into three groups with each group having serial measurements of the rate of absorption of either $100 \mathrm{mM} \mathrm{L}$-glucose $(n=5), 100 \mathrm{mM} 30 \mathrm{OMG}$ $(n=10)$, or $5 \mathrm{mM}$ 3OMG $(n=6)$. The absorption rate of $5 \mathrm{mM}$ 3OMG was used to determine changes in the resistance of the UWL $(21,22)$. The rats were fasted for $4 \mathrm{~h}$ before performing each measurement and transfused with donor blood after each experiment to prevent anemia. These rats weighed $270 \pm 20$ grams before catheter placement. The average weight during the study period decreased to $240 \pm 20 \mathrm{gms}$ on the fourth postoperative day and then increased to $260 \pm 20$ grams on the sixth postoperative day.

The effect of anesthesia alone was determined by measuring the rate of $30 \mathrm{MG}$ absorption at a concentration of $100 \mathrm{mM}$ before and after anesthesia in a group of rats in which catheters had been placed at least four days previously $(n=10)$. The rats were NPO for $3 \mathrm{~h}$ before the initial measurement. An hour later they were anesthetized with the same anesthesia that was used for the initial catheter placement. One half hour later the rate of 3OMG absorption was measured again.

To determine the characteristics of glucose absorption without the influence of surgical bowel manipulation, the rates of L-glucose and 3OMG absorption were measured serially at luminal concentrations of $5,20,50,100,200$, and $400 \mathrm{mM}$ using the dual infusion method in twelve rats starting at least $4 \mathrm{~d}$ after catheter placement. 3OMG and L-glucose absorption were measured in each rat at one of the above concentrations on the same day. 3OMG absorption was measured after a 3-h fast followed two hours later by measurement of L-glucose absorption at the same concentration. 3OMG absorption was measured before L-glucose absorption because the faster rate of absorption would ensure that all luminal 3OMG would be absorbed before the infusion of $L$ glucose. Studies were performed only if a rat's weight on the fourth postoperative day was at least $95 \%$ of its preoperative weight. In this group of rats, the average weights preoperative and on the fourth postoperative day were $300 \pm 20$ gms and $300 \pm 20$ gms, respectively.

Analytical methods. Blood samples $(0.25 \mathrm{ml})$ were added to $0.3 \mathrm{ml}$ of $1.0 \mathrm{M} \mathrm{HClO}_{4}$ and centrifuged for $5 \mathrm{~min}$ at $17,000 \mathrm{rpm}$ in a Microfuge $\mathrm{E}^{\mathrm{TM}}$ (Beckman Instruments, Palo Alto, $\mathrm{CA}$ ). The tubes, in which the samples were placed, were weighed empty, after the addition of $\mathrm{HClO}_{4}$, and then after the addition of the blood sample to calculate the amount of dilution of the sample by $\mathrm{HClO}_{4}$. Duplicate $0.1-\mathrm{ml}$ aliquots of the supernatant were then counted in $5 \mathrm{ml}$ of scintillation fluid (EcoLume ${ }^{\circledR}$; ICN, Costa Mesa, CA). The radioactivity was measured in a Mark V scintillation counter (model 5303). The windows in the scintillation counter were adjusted so that all of the $\left[{ }^{3} \mathrm{H}\right]$ was in one channel only. The amount of cross over of $\left[{ }^{14} \mathrm{C}\right]$ into this channel was then calculated using standards.

Calculation of glucose transport kinetics. We calculated the kinetics of glucose absorption using an analysis similar to Meddings and Westergaard (8). Meddings and Westergaard showed that the best model for describing intestinal glucose absorption in vivo is a model which has a single carrier plus passive diffusion and accounts for the unstirred water layer (UWL). Since we cannot precisely determine the length of intestine exposed to our duodenal infusion, we did not standardize our results to length. Instead, we standardized our values to a $1 \mathrm{ml}$ bolus given over $0.6 \mathrm{~min}$.

The resistance (R) of the UWL was determined from the rate of 3OMG absorption $\left(J_{30 \mathrm{MG}}\right)$ at a concentration of $5 \mathrm{mM}$ using the following equation:

$J_{3 \mathrm{MMG}}=\left(C_{1}-C_{2}\right) / R$

where $J_{30 M G}$ is the rate of movement of $30 \mathrm{OG}$ across a diffusion barrier, $C_{1}$ is the concentration of solute in the bulk solution, and $C_{2}$ is the concentration of solute at the microvillus interface $(16,21,22) . C_{1}$ is equal to the concentration of $30 \mathrm{MG}$ in the duodenal infusion ( $5 \mathrm{mM}$ ) corrected for dilution by luminal contents as determined in preliminary experiments described below. Since $30 \mathrm{MG}$ is rapidly absorbed at the microvillus interface, we assumed that $C_{2}=0$. We also assumed that there was no accumulation of 3OMG in any compartment so that flow through the UWL is the same as the flow through the intestinal mucosa which is the same as total absorption, $J_{3 \mathrm{OMG}}(9)$.

Membrane permeability (P) was calculated using the rate of absorption of L-glucose $\left(\mathrm{J}_{\mathrm{L}-\text { glucose }}\right)(8)$. Because L-glucose is only passively absorbed,

$P=\left(J_{\mathrm{L}-\text { glucose }}\right) /\left(C_{2}\right)$

From Eq. 1, $C_{2}=C_{1}-\left(J_{\mathrm{L}}\right)(R)$. Therefore,

$P=\left(J_{\mathrm{L}-\text { glucose }}\right) /\left[C_{1}-\left(J_{\mathrm{L}-\text { glucose }}\right)(R)\right]$

or

$1 / P=\mathrm{C}_{1} / J_{\mathrm{L}-\mathrm{glucose}}-R$

$J_{\mathrm{L} \text {-glucose }} / \mathrm{C}_{1}$ in $\mu$ moles/min per $\mathrm{mM}$ is the slope of the rate of $\mathrm{L}$-glucose absorption vs concentration.

If we assume that active carrier-mediated glucose transport in the intestine follows first order kinetics, then an Eadie-Hofstee plot of active transport $/ C_{2}$ vs active transport is linear and the $K_{\mathrm{m}}$ (Michaelis-Menten constant) is equal to the negative of the slope of this line and $V_{\max }$ (maximum transport velocity) is equal to the $y$-intercept. Since active transport $\left(\mathrm{J}_{\text {active }}\right)$ is total glucose absorption less passive absorption, $\mathrm{J}_{\text {active }}$ $=J_{30 M G}-(P)\left(C_{2}\right)$. A plot of $J_{\text {active }} / C_{2}$ vs $J_{\text {active }}$ was made and the slope and $y$ - intercept determined by linear regression. 
Statistical analysis. Comparisons of the effect of surgical bowel manipulation on 3OMG and L-glucose absorption were performed by two-factor ANOVA with repeated measures. Two-tailed paired $t$ tests were used to determine the effect of anesthesia alone on 3OMG absorption and to compare the measurements of 3OMG absorption by the dual infusion method and the perfusion method. The effect of time after surgical bowel manipulation on the extent of dilution of PEG by intestinal contents was analyzed by one-way ANOVA. All values are expressed as mean \pm SD.

\section{Results}

Verification of the dual infusion method for measuring intestinal glucose absorption

Comparison of dual infusion method with the intestinal perfusion method. Since perfusion of an isolated loop of intestine has been the primary method for measuring intestinal glucose absorption in vivo, we verified our method by comparing measurements of the rate of glucose absorption obtained simultaneously by the dual infusion method described above and the perfusion method. In 10 rats, an intestinal loop was perfused with $50 \mathrm{mM} 30 \mathrm{MG}$ and intestinal $30 \mathrm{MG}$ absorption was performed simultaneously by the dual infusion method and by measuring the rate of disappearance of 30MG from the perfusate.

In 10 rats ( $320 \pm 60$ grams), an intestinal loop was isolated after placement of the vascular catheters. The surgical procedure was the same as previously described except for the following alterations (1). The duodenum was ligated $\sim 1 \mathrm{~cm}$ proximal to the catheter insertion site with No. 2 silk suture. A $20-\mathrm{cm}$ length of 5-mm O.D. silicone tubing (IMED Corp., San Diego, CA) was pulled through an abdominal incision made in the left lower quadrant. A segment of jejunum $27 \pm 11 \mathrm{~cm}$ distal to the duodenal catheter was ligated and cut proximal to the ligation. The tubing was then inserted $\sim 1 \mathrm{~cm}$ into the open proximal end of the jejunum and secured with two circumferential No 2 silk sutures. The isolated loop was then flushed with $0.9 \%$ saline until clear. The intestines were returned to the peritoneal cavity and the abdomen closed as described above.

The cannulated loop was connected to a syringe pump proximally and a collecting chamber distally. Postoperatively, the loop was perfused with a solution containing $130 \mathrm{meq} / \mathrm{L} \mathrm{Na}$, $109 \mathrm{meq} / \mathrm{L} \mathrm{Cl}, 4 \mathrm{meq} / \mathrm{L} \mathrm{K}, 3 \mathrm{meq} / \mathrm{L} \mathrm{Ca}$ and $28 \mathrm{meq} / \mathrm{L}$ lactate at $1.0 \mathrm{ml} / \mathrm{min}$ for $30 \mathrm{~min}$. The perfusate was changed to the same solution as above but also containing $50 \mathrm{mM}$ of $30 \mathrm{MG}$ and tracer amounts of $\left[{ }^{3} \mathrm{H}\right] 30 \mathrm{OMG}(1.5 \mu \mathrm{Ci} / \mathrm{ml})$ and $\left[{ }^{14} \mathrm{C}\right]$ polyethylene glycol $(4 \mathrm{kD} ; 0.02 \mu \mathrm{Ci} / \mathrm{ml})$. The solution was balanced with water to maintain iso-osmolarity. $\left[{ }^{14} \mathrm{C}\right] \mathrm{PEG}$ was used to correct for net water absorption. A single pass perfusion was done at a rate of $1.0 \mathrm{ml} / \mathrm{min}$ for $30 \mathrm{~min}$. The perfusate was collected over one minute intervals during the perfusion. A constant infusion of $\left[{ }^{14} \mathrm{C}\right] 30 \mathrm{MG}$ was delivered through the portal venous catheter at a rate of $0.09 \mathrm{ml} / \mathrm{min}$ during the perfusion.

Blood samples were drawn from the aorta catheter at $2 \mathrm{~min}$ intervals during the perfusion. Blood samples were analyzed for $\left[{ }^{3} \mathrm{H}\right]$ and $\left[{ }^{14} \mathrm{C}\right]$, and glucose uptake was calculated as described above for the dual infusion method. Duplicate $0.1-\mathrm{ml}$ aliquots were collected from the samples of perfusate and counted directly with $5 \mathrm{ml}$ of scintillation fluid (EcoLume ${ }^{-}$ICN, Costa Mesa, CA $)$. The $\mathrm{cpm} / \mathrm{ml}$ of $\left[{ }^{3} \mathrm{H}\right]$ and $\left[{ }^{14} \mathrm{C}\right]$ in the perfusate was
Table I. Comparison of 30MG Absorption: Dual Infusion vs Perfusion

\begin{tabular}{cccc}
\hline Rat No. & Dual infusion & Perfusion & Percent difference \\
\hline 1 & 1.78 & 1.27 & 34.0 \\
2 & 2.20 & 2.03 & 7.9 \\
3 & 1.96 & 1.93 & 1.9 \\
4 & 2.12 & 1.92 & 10.1 \\
5 & 2.15 & 3.17 & 38.6 \\
6 & 2.08 & 0.98 & 71.7 \\
7 & 1.59 & 1.58 & 0.8 \\
8 & 1.45 & 1.80 & 21.7 \\
9 & 1.43 & 1.92 & 28.6 \\
10 & 1.11 & 1.61 & 36.1 \\
Ave \pm SD. & $1.79 \pm 0.37$ & $1.82 \pm 0.58$ & $24.1 \pm 21.7$ \\
\end{tabular}

After surgical placement of portal venous and aortic catheters, a segment of intestine was isolated and cannulated at its proximal and distal ends. The intestinal loop was perfused with an isotonic solution containing $50 \mathrm{mM}$ 3OMG with tracer amounts of $\left[{ }^{14} \mathrm{C}\right]$ PEG and $\left[{ }^{3} \mathrm{H}\right]$ 3OMG.

Simultaneously tracer amounts of $\left[{ }^{14} \mathrm{C}\right] 3 \mathrm{OMG}$ were constantly infused into the portal vein. Serial aortic blood samples were drawn and the perfusate was collected after passage through the intestine. The rate of $30 \mathrm{MG}$ absorption ( $\mu \mathrm{moles} / \mathrm{min}$ per $10 \mathrm{~cm}$ of intestine) was calculated by the perfusion method and compared with the rate calculated by the dual infusion method.

measured before and after passage through the intestinal loop. The concentration of $\left[{ }^{3} \mathrm{H}\right]$ was corrected for net water absorption. The absorption rate of $30 \mathrm{MG}$ was calculated from the perfusion method as follows:

Rate of 3OMG absorption

$=\left[\left(\left[{ }^{3} \mathrm{H}\right] \mathrm{cpm}_{\text {initial }}-\left[{ }^{3} \mathrm{H}\right] \mathrm{cpm}_{\text {final }}\right) \times\right.$ infusion rate $]$

$\div$ specific activity of $\left[{ }^{3} \mathrm{H}\right]$

At the conclusion of the experiment, the animal was sacrificed and the length of the isolated intestinal loop was measured.

We found that there was no difference between the rate of absorption of $50 \mathrm{mM} 3 \mathrm{OMG}$ as measured by these two methods in acutely laparotomized, and anesthetized rats (Table I). Therefore, the dual infusion method is a valid method for measuring intestinal glucose absorption. The disagreement we find between our results using the dual infusion method and the results of previous studies using the perfusion method appears to be due to the conditions under which the experiments were performed (acute vs. chronic). The rate of absorption of 50 $\mathrm{mM} 30 \mathrm{OMG}$ in these acute experiments was $57 \%$ less than the rate under chronic conditions ( see Table IV) when standardized to the length of intestine perfused. This is despite the fact that in these acute experiments the volume within the intestinal lumen and, therefore, surface area exposed to the infusate was greater because the constant perfusion of $1 \mathrm{ml} / \mathrm{min}$ dilated the intestine whereas the $1 \mathrm{ml}$ bolus infusion in the chronic experiments caused minimal intestinal dilation.

Dilution of duodenal infusion. In chronically catheterized rats, infusions of substrates into the intestine may be diluted by luminal contents already present and, therefore, we cannot determine the exact luminal concentration of a substrate after in it is infused into the intestine. In the accompanying paper, 
Table II. Dilution of Polyethylene Glycol after Infusion Into the Intestine

\begin{tabular}{lccccc}
\hline \multicolumn{1}{c}{ Time after laparotomy } & $0 \mathrm{~h}$ & $4 \mathrm{~h}$ & $1 \mathrm{~d}$ & $2 \mathrm{~d}$ & $6 \mathrm{~d}$ \\
\hline No. of measurements & 11 & 10 & 8 & 5 & 4 \\
Dilution of PEG (\%) (mean \pm SD) & $12.8 \pm 10.4$ & $9.6 \pm 8.8$ & $14.8 \pm 10.4$ & $20.2 \pm 8.1$ & $12.0 \pm 16.9$ \\
\hline
\end{tabular}

In rats that had two duodenal catheters in place, the amount that an infusion of $\left[{ }^{14} \mathrm{C}\right]$ PEG into the duodenum was diluted was measured immediately after laparotomy and then $4 \mathrm{~h}, 1 \mathrm{~d}, 2 \mathrm{~d}$, and $6 \mathrm{~d}$ later. $1 \mathrm{ml}$ of isotonic saline containing tracer quantities of $\left[{ }^{14} \mathrm{C}\right]$ PEG $(4 \mathrm{kD})$ was infused into the proximal duodenal catheter followed by aspiration of fluid from the distal catheter. The concentration of $\left[{ }^{14} \mathrm{C}\right]$ PEG from the a spirated fluid was compared to the concentration of $\left[{ }^{14} \mathrm{C}\right]$ PEG infused. PEG, polyethylene glycol.

we found that a $1.0-\mathrm{ml}$ duodenal infusion was diluted by $15.7 \%$ in our chronically catheterized rats at least $4 \mathrm{~d}$ after laparotomy. To determine whether this dilution is different at the various times after catheter placement, the dilution of a nonabsorbable indicator, polyethylene glycol (4 kD), was determined at various times after surgery in a group of rats in which two duodenal catheters were place $1 \mathrm{~cm}$ apart. The surgical procedure and method were described in detail in the accompanying paper (1).

Immediately postoperative and then $4 \mathrm{~h}, 1 \mathrm{~d}, 2 \mathrm{~d}$, and $6 \mathrm{~d}$ later, $1.0 \mathrm{ml}$ of $0.9 \% \mathrm{NaCl}$ with tracer amounts of $\left[{ }^{14} \mathrm{C}\right] \mathrm{PEG}$ was infused into the proximal duodenal catheter at various postoperative times. After the infusion was complete, fluid was aspirated from the distal catheter. $0.05-\mathrm{ml}$ aliquots of the aspirated fluid were mixed with $5 \mathrm{ml}$ of scintillation fluid. The samples were then analyzed for $\left[{ }^{14} \mathrm{C}\right]$ concentrations and compared to standards from the infusate. We calculated as decrease in the concentration of PEG in the fluid aspirated from the duodenum as a percentage of the concentration of PEG that was infused. The rats were NPO for $4 \mathrm{~h}$ before performing these studies.

There were no significant differences in the dilution of PEG after a $1.0 \mathrm{ml}$ bolus into the duodenum at any time after laparotomy (Table II). The mean dilution of PEG after infusion into the intestine for all measurements was $13 \pm 11 \%$ of the concentration that was infused. The slight difference in the dilution in this group of experiments compared to those described in the accompanying paper ( 13 vs. $15.7 \%$ ) reflects slightly different performances of the experiment.

Comparison of L-glucose vs $3 O M G$ with phloridzin for measuring passive glucose absorption. Since many previous studies of intestinal glucose absorption use phloridzin, an inhibitor of active glucose transport, to measure passive absorption of glucose, measurements of passive glucose absorption using L-glucose at $100 \mathrm{mM}$ were compared to measurements of passive absorption using $30 \mathrm{MG}$ at $100 \mathrm{mM}$ with phloridzin at $0.5 \mathrm{mM}$ in the same five rats. Previous studies show that active glucose transport is completely inhibited by phloridzin at a concentration of $0.5 \mathrm{mM}$ (2) (23). In this study, L-glucose was used to measure passive absorption because experiments were performed serially in the same animals and the inhibitory effects of phloridzin may have adversely affected subsequent measurements.

In five rats, passive absorption of glucose was determined first by using $100 \mathrm{mM}$ L-glucose and then $24 \mathrm{~h}$ later by using $100 \mathrm{mM} 30 \mathrm{MG}$ with $0.5 \mathrm{mM}$ phloridzin. Absorption of Lglucose $(2.0 \pm 1.4 \mu \mathrm{moles} / \mathrm{min})$ and absorption of $30 \mathrm{MG}$ with phlorizdin $(2.8 \pm 1.8 \mu \mathrm{moles} / \mathrm{min})$ was not significantly different $(P=0.13)$.

\section{Effect of laparotomy and anesthesia on glucose absorption}

The rate of 3OMG absorption was significantly reduced immediately after laparotomy with anesthesia (Table III). The rate of absorption of 3OMG immediately after laparotomy and 4 hours later was 86 and $62 \%$ less than at six days postoperative increasing from $2.1 \pm 1.6 \mu$ moles $/$ min immediately after laparotomy to $14.6 \pm 3.4 \mu \mathrm{moles} / \mathrm{min}$. The rate of absorption of 100 $\mathrm{mM}$ L-glucose was not significantly altered by laparotomy with anesthesia at any time (Table III).

The fraction of active transport calculated from the mean values of the rate of absorption of $3 \mathrm{OMG}$ and L-glucose at each time point increased from $71 \%$ immediately after laparotomy to $95 \%$ at $6 \mathrm{~d}$ after surgery.

Table III. Effect of Laparotomy and Anesthesia on Intestinal Absorption of 3OMG and L-Glucose

\begin{tabular}{lccccc}
\hline & \multicolumn{4}{c}{ Time after laparotomy } \\
\cline { 2 - 5 } & $0 \mathrm{~h}$ & $4 \mathrm{~h}$ & $1 \mathrm{~d}$ & $2 \mathrm{~d}$ & $6 \mathrm{~d}$ \\
\hline $\mathrm{J}_{\text {3OMG }} 100 \mathrm{mM}$ & $2.1 \pm 1.6^{*}$ & $5.5 \pm 3.5^{* \ddagger}$ & $12.2 \pm 5.2^{\ddagger}$ & $16.2 \pm 3.4^{\ddagger}$ & $14.6 \pm 3.4$ \\
$\mathrm{~J}_{\text {3OMG }} 5 \mathrm{mM}$ & $0.3 \pm 0.1^{*}$ & $0.3 \pm 0.1^{*}$ & $0.9 \pm 0.3^{\ddagger}$ & $1.3 \pm 0.2^{\ddagger}$ & $1.1 \pm 0.2$ \\
$\mathrm{R}(\mathrm{mM} /[\mathrm{moles} / \mathrm{min}])$ & $14.1 \pm 5.6$ & $12.2 \pm 3.7$ & $5.0 \pm 1.3$ & $3.5 \pm 0.7$ & $3.8 \pm 0.7$ \\
$\mathrm{~J}_{\text {L-glucose }} 100 \mathrm{mM}$ & $0.6 \pm 0.2$ & $1.1 \pm 0.5$ & $1.3 \pm 1.0$ & $1.2 \pm 0.9$ & $0.8 \pm 0.8$ \\
Active absorption $(\%)$ & 71 & 80 & 89 & 93 & 95
\end{tabular}

The absorption of rates of $30 \mathrm{MG}\left(\mathrm{J}_{3 \mathrm{OMG}}\right)$ at $100 \mathrm{mM}(n=10)$ and $5 \mathrm{mM}(n=5)$ and the absorption rate of L-glucose $\left(\mathrm{J}_{\mathrm{L}-\mathrm{glucose}}\right)$ at $100 \mathrm{mM}(n$ $=6$ ) were measured immediately after laparotomy $(0 \mathrm{~h})$ and the $4 \mathrm{~h}, 1 \mathrm{~d}, 2 \mathrm{~d}$, and $6 \mathrm{~d}$ later. The resistance (R) of the unstirred water layer was calculated from the $\mathrm{J}_{3 \mathrm{OMG}}$ at $5 \mathrm{mM}$. The percentage of absorption occurring by active transport at $100 \mathrm{mM}$ was calculated as $\left(\mathrm{J}_{30 \mathrm{MG}}-\mathrm{J}_{\mathrm{L}-\mathrm{glucose}}\right) /$ $\mathrm{J}_{3 \mathrm{OMG}} \times 100 \%$. Absorption rates are in $\mu$ moles $/ \mathrm{min}$. ${ }^{*} P<0.05$ vs $6 \mathrm{~d} ;{ }^{\ddagger} P<0.05$ from previous measurement. 


\begin{tabular}{|c|c|c|c|c|c|c|}
\hline & \multicolumn{6}{|c|}{ Concentration (mM) } \\
\hline & 5 & 20 & 50 & 100 & 200 & 400 \\
\hline $\mathrm{J}_{3 \mathrm{OMG}}$ & $1.3 \pm 0.5$ & $4.1 \pm 1.1$ & $7.1 \pm 2.3$ & $13.1 \pm 2.1$ & $15.4 \pm 3.9$ & $19.0 \pm 3.2$ \\
\hline $\mathrm{J}_{\mathrm{L} \text {-glucose }}$ & $0.1 \pm 0.1$ & $0.4 \pm 0.2$ & $1.0 \pm 0.5$ & $1.6 \pm 0.5$ & $2.7 \pm 1.2$ & $4.5 \pm 2.6$ \\
\hline $\mathrm{J}_{\text {active }}$ & $1.2 \pm 0.5$ & $3.7 \pm 1.0$ & $6.1 \pm 1.9$ & $11.5 \pm 2.4$ & $12.7 \pm 4.1$ & $14.5 \pm 2.8$ \\
\hline Active transport (\%) & $89 \pm 3$ & $91 \pm 4$ & $86 \pm 4$ & $87 \pm 5$ & $81 \pm 10$ & $77 \pm 10$ \\
\hline
\end{tabular}

The rate of 3OMG and L-glucose absorption ( $\mathrm{J}_{3 \mathrm{OMG}}$ and $\mathrm{J}_{\mathrm{L}-\text { glucose }}$ ) were measured at luminal concentrations of 5, 20, 50, 100, 200, and 400 mM by the dual infusion method. All measurements were performed at least $4 \mathrm{~d}$ after catheter placement. Active transport ( $\left.\mathbf{J}_{\text {active }}\right)$ was calculated as $\mathbf{J}_{30 \mathrm{GG}}$ - $\mathrm{J}_{\mathrm{L} \text {-glucose }}$ for each rat. The percentage of absorption occurring by active transport was calculated as $\mathrm{J}_{\text {active }} / \mathrm{J}_{3 \mathrm{OMg}} \times 100 \%$. Values are mean $\pm \mathrm{SD}$ in $\mu \mathrm{moles} / \min (n=11)$.

The resistance $(R)$ of the unstirred water layer (UWL) calculated from the rate of absorption of $5 \mathrm{mM} 30 \mathrm{MG}$ was also significantly increased after surgical bowel manipulation. The rate of $5 \mathrm{mM} 30 \mathrm{OMG}$ absorption was decreased $73 \%$ immediately after laparotomy compared to the rate on the sixth postoperative day. $\mathrm{R}$ decreased from $14.1 \mathrm{mM} /(\mu \mathrm{moles} / \mathrm{min})$ immediately postoperative to $3.8 \mathrm{mM} /(\mu \mathrm{moles} / \mathrm{min})$ on the sixth postoperative day.

Anesthesia alone also significantly decreased the rate of absorption of 3OMG. Absorption of $100 \mathrm{mM} 30 \mathrm{MG}$ decreased from $12.1 \pm 3.1 \mu \mathrm{moles} / \mathrm{min}$ prior to anesthesia to $8.9 \pm 3.7$ $\mu$ moles/min while under anesthesia $(P=0.049)$.

\section{Intestinal glucose absorption in chronically catheterized rats}

Absorption rates of $30 \mathrm{MG}$ and L-glucose at luminal concentrations from $5 \mathrm{mM}$ to $400 \mathrm{mM}$ are shown in Table IV. Since 3OMG absorption measures both active transport and passive absorption and L-glucose is absorbed only passively, active transport was calculated as the difference between 3OMG and L-glucose absorption. The fraction of active transport of glucose decreased from $\sim 90 \%$ at luminal concentrations of 5 and 20 $\mathrm{mM}$ to $77 \%$ at a luminal concentration of $400 \mathrm{mM}$. As expected, absorption of L-glucose (passive absorption) was linear at luminal concentrations from $5 \mathrm{mM}$ to $400 \mathrm{mM}\left(\mathrm{r}^{2}=0.98\right.$, slope $=0.011 \mu \mathrm{moles} / \mathrm{min}$ per $\mathrm{mM}$ ).

We calculation of the kinetics of glucose transport assuming that the intestinal infusions of 3OMG or L-glucose were diluted by $13 \%$. $\mathrm{R}$ and $\mathrm{P}$ were $3.3 \mathrm{mM} /(\mu$ moles $/ \mathrm{min})$ and 0.014 $\mu \mathrm{moles} / \mathrm{min} / \mathrm{mM}$, respectively. After accounting for the resistance (R) of the unstirred water layer, the $K_{\mathrm{m}}$ was $11.3 \mathrm{mM}$ and $V_{\max }$ was $15.6 \mu \mathrm{moles} / \mathrm{min}$.

To compare our estimate of $V_{\max }$ with previous estimates by others, we determined the length of intestine exposed to a 1-ml duodenal infusion. In five, anesthetized, chronically catheterized rats, $1 \mathrm{ml}$ of isotonic saline containing Evan's blue dye was infused into the duodenal catheter. After the infusion, a laparotomy was performed. We found that $16.8 \pm 5.7 \mathrm{~cm}$ of intestine contained Evan's blue dye $2.5 \mathrm{~min}$ after the start of the duodenal infusion. Thus, our estimate of $V_{\max }$ is $0.93 \mu \mathrm{moles} / \mathrm{min} / \mathrm{cm}$ of intestine. Our measurement of the length of intestine perfused by the Evan's blue dye is the length containing any dye regardless the degree of staining. In addition, because the intestinal segment perfused by the dye is not dilated, the surface area exposed to the duodenal infusion is less per unit length. There- fore, the effective length and surface area of the intestine that is perfused is less, and we are underestimating $V_{\max }$.

\section{Discussion}

We developed a method for measuring intestinal glucose absorption in unanesthetized, unrestrained animals without the effects of acute surgical bowel manipulation. In addition, multiple serial experiments can be performed on the same animal minimizing interanimal variability.

Using this chronically catheterized rat model, this study shows that surgical manipulation of the bowel with anesthesia causes an $86 \%$ decrease in the absorption rate of 3OMG. Anesthesia alone decreased the absorption rate of 3OMG by only $23 \%$. There was not a significant effect on absorption of $\mathrm{L}-$ glucose. Since $30 M G$ is passively and actively transported in the same manner as D-glucose, and L-glucose is only passively absorbed, the major effect of surgical bowel manipulation and anesthesia was inhibition of active glucose transport. The fraction of glucose transport that is active at luminal glucose concentrations of $100 \mathrm{mM}$ increased from $71 \%$ immediately after surgery to $95 \% 6 \mathrm{~d}$ after surgery. The effect of surgical bowel manipulation was present for $24 \mathrm{~h}$.

In chronically catheterized rats without the influence of surgical bowel manipulation, most glucose is actively absorbed by the intestine even at luminal concentrations as high as $400 \mathrm{mM}$. Using the dual infusion method, 87 to $77 \%$ of glucose was absorbed actively at luminal concentrations from 100 to 400 $\mathrm{mM}$. We calculated the $K_{\mathrm{m}}$ and $V_{\max }$ of active glucose transport after correction for the effects of the unstirred water layer. To calculate the resistance $(R)$ of the unstirred water layer, we assumed that $C_{2}=0$. Thus, we calculated the maximum effect of the UWL, because $C_{2}$ may actually be slightly greater than 0 decreasing $\mathrm{R}$ as calculated in Eq. 2. Even after accounting for the maximal resistance of the UWL, the $K_{\mathrm{m}}$ and $V_{\max }$ for carrier-mediated glucose absorption were $11.3 \mathrm{mM}$ and 15.6 $\mu$ moles/min $(0.93 \mu \mathrm{moles} / \mathrm{min}$ per $\mathrm{cm})$, respectively.

The results of this study imply that surgical bowel manipulation and anesthesia also adversely affects active transport of D-glucose. 3OMG is actively transported at the brush border membrane by the major sodium-dependent transporter that transports D-glucose. Fedorak et al. showed that the $K_{\mathrm{m}}$ for D-glucose and 3OMG are similar but that the $V_{\max }$ was $\sim 30 \%$ less (7). Thomson et al. showed that the rate of 3OMG uptake 
in rats was $40 \%$ less than for D-glucose at luminal concentrations of $40 \mathrm{mM}(10)$. In addition, L-glucose accurately estimates the passive absorption of D-glucose $(6,8,9,10)$. Thus, the effects of surgical bowel manipulation and anesthesia on D-glucose absorption are comparable with the effects on $30 \mathrm{MG}$ absorption.

The adverse effect of surgical bowel manipulation on intestinal absorptive function is consistent with previous studies. $\mathrm{Ki}$ mura et al. showed that portal venous and aortic blood concentrations of glucose and lactate after an intragastric bolus of glucose increased at a slower rate immediately postoperative compared to subsequent measurements (24). Singh et al. showed decreased D-xylose absorption for $48 \mathrm{~h}$ after laparotomy in rats and concluded that measurements of gut absorptive capacity should be performed at least $3 \mathrm{~d}$ after laparotomy (25).

The relatively high rate of glucose absorption using our chronically catheterized rat model is consistent with other studies performed without the influence of surgical bowel manipulation and anesthesia. Using a constant perfusion method through a triple-lumen tube in humans, Fine et al. showed that $91.6 \%$ of glucose was actively absorbed at luminal glucose concentrations of $120 \mathrm{mM}$ (26). Using a similar method in combination with measuring transmucosal potential differences, Sparso et al. showed that the $K_{\mathrm{m}}$ after correction for the UWL was 25.8 $\mathrm{mM}$ (27).

Most other studies of intestinal glucose absorption, however, have used methods in which the intestine has been acutely manipulated surgically. These studies claim that the $K_{\mathrm{m}}$ after correction for the resistance of the unstirred water layer ranges between 0.1 and $2 \mathrm{mM}(4,8,28-30)$. Some of these studies also report that passive absorption of glucose begins to exceed active transport of glucose at intestinal luminal concentrations as low as 35 to $60 \mathrm{mM}(2-5)$. Estimates of the maximum active transport velocity $\left(V_{\max }\right)$ range from 0.2 to $0.6 \mu$ moles/ min per $\mathrm{cm}$ of intestine $(2,4,8,31)$. The lower rates of active glucose transport in these studies is probably secondary to the effects of surgical bowel manipulation and anesthesia.

One possible explanation for the decrease in intestinal absorption of $30 \mathrm{MG}$ after laparotomy is an increase in the resistance $(R)$ of the UWL $(16,32)$. The unstirred water layer acts as a preepithelial diffusion barrier. Anderson using a chronic method of intestinal perfusion showed that the unstirred water layer was approximately six fold greater in the anesthetized, acutely laparotomized rat than in the nonanesthetized, nonlaparotomized rat (21). Similarly, we found that $R$ was 3.7-fold greater immediately postoperative and $4 \mathrm{~h}$ later compared to 6 d later.

To determine whether the effect of surgical bowel manipulation on the intestinal glucose absorption was secondary to the increase in $R$, we calculated the change in $C_{2}$ using Eq. 1 based on changes in $\mathbf{R}$ after surgical bowel manipulation assuming that $V_{\max }$ and $K_{\mathrm{m}}$ remained unchanged at $15.6 \mu \mathrm{moles} / \mathrm{min}$ and $11.3 \mathrm{mM}$. Predicted rates of active transport $\left(\mathrm{J}_{\text {active }}{ }^{*}\right)$ and of total transport $\left(\mathrm{J}_{3 \mathrm{OMG}} *\right.$ ) were calculated based on these changes in $\mathrm{C}_{2}$ using Eqs. 5 and 6 (8).

$$
\begin{aligned}
& J_{\text {active }} *=V_{\max } /\left(1+K_{\mathrm{m}} / C_{2}\right) \\
& J_{\text {3OMG }} *=J_{\text {active }} *+(P)\left(C_{2}\right)
\end{aligned}
$$

Even with an increase in $\mathrm{R}$ from $3.8 \mathrm{mM} /(\mu$ moles $/ \mathrm{min})$ to 14.1 $\mathrm{mM} /(\mu \mathrm{moles} / \mathrm{min}), \mathrm{J}_{\text {active }}$ and $\mathrm{J}_{\text {3OMG }}$ immediately postoperative were only 11 and $15 \%$ of predicted if $V_{\max }$ and $K_{\mathrm{m}}$ remained unchanged. At $4 \mathrm{~h}$ postoperative, $\mathrm{J}_{\text {active }}$ and $\mathrm{J}_{3 \mathrm{OMG}}$ were 47 and $57 \%$ of predicted rates. Predicted and actual absorption rates were essentially the same $1 \mathrm{~d}$ after surgical bowel manipulation. Therefore, while changes in the UWL after surgical bowel manipulation decreased glucose absorption, most of the decrease was due a decrease in $\mathbf{J}_{\text {active. }}$. The facts that surgical bowel manipulation did not significantly decrease L-glucose absorption and that our $K_{\mathrm{m}}$ and $V_{\max }$ after correction for $\mathrm{R}$ were higher than in acute studies also suggest that the increase in $R$ does not entirely explain the decrease in intestinal absorption after laparotomy.

The perfusion method has traditionally been the "gold standard" for measuring intestinal absorption of substances. Since it is usually performed after acute surgical bowel manipulation and anesthesia the results obtained from this method will be influenced by the effects of surgery and anesthesia.

In acute models of intestinal function, intestinal absorption may be inhibited because of changes in total splanchnic blood flow or changes in microvascular blood flow. Surgical bowel manipulation, anesthesia, and restraint decrease the amount of intestinal blood flow and change the distribution of intestinal blood flow $(33,34)$. Intestinal absorption of glucose and other substances are decreased when intestinal blood flow is decreased $(9,11,35)$.

Nicholls et al. using an acute perfusion model showed that most luminal glucose was metabolized to lactate in the intestine (36). Using a chronically catheterized rat model, however, Rich-Denson and Kimura showed that almost all luminal glucose was absorbed intact and not metabolized to lactate by the intestine (37). The results obtained in the Nicholls' acute study were duplicated in the chronic study only if the chronically catheterized rats were placed in a hypoxic environment with an $\mathrm{FiO}_{2}$ of 0.07 indicating that cellular energy levels are low even though the blood oxygen levels are normal. We hypothesize that this decrease in cellular energy may be the result of a decrease in intestinal microvascular blood flow. A decrease in microvascular blood flow may occur despite relatively intact splanchnic blood flow because of shunting of blood through larger vessels.

In addition, the perfusion of an isolated intestinal loop may alter intestinal transport due to the effects of luminal distension and increases in luminal hydrostatic pressure $(38,39,40,41)$. Harris et al. showed that luminal distension of the rat ileum decreased sodium absorption and resulted in secretion of sodium bicarbonate (42). Increases in intraluminal pressure inhibited water absorption. Hollander et al. showed that increases in the luminal flow rate and increases in intraluminal pressure decreased rat jejunal permeability to polyethylene glycol ( $900 \mathrm{~mol}$ wt) and water transport changed from net absorption to net secretion (43).

The dual infusion method for measuring glucose and amino acid absorption was previously described $(20,44)$. In the present study, the method was modified to eliminate some of the assumptions in the previous studies. 3OMG and L-glucose were used to avoid the need to make any assumption regarding metabolism. In addition, by constantly infusing tracer amounts of $\left[{ }^{14} \mathrm{C}\right] 30 \mathrm{MG}$ and $\left[{ }^{14} \mathrm{C}\right] \mathrm{L}$-glucose directly into the portal vein, we have accounted for any first-pass effect by liver. In this study, the dual infusion method was verified by comparing simultaneous measurements of intestinal 3OMG absorption obtained by this method and the perfusion of an isolated intestinal 
loop method, which previously was the primary method of measuring intestinal absorption in vivo. Although these studies were performed under conditions of anesthesia and acute surgical bowel manipulation, the similarity of the results obtained by these two methods indicates that the dual infusion method is an accurate method for determining intestinal absorption.

As discussed in the accompanying paper, dilution of our duodenal infusion by intestinal contents may decrease the luminal concentrations of $30 \mathrm{OMG}$ and L-glucose (1). However, we found that infusions into the duodenum were only diluted $13 \%$. There was not any significant differences in the dilution of PEG at any time after surgery. Thus, the changes in intestinal glucose absorption after surgical bowel manipulation are not secondary to changes in the dilution of substrate. This dilution factor was also used in the calculations of $K_{\mathrm{m}}$ and $V_{\max }$ and does not significantly changes our results.

Using our method, we cannot accurately determine the length of intestine exposed to the infused substrate. As suggested by others, however, expression of intestinal absorption characteristics per unit surface area has little meaning since the surface area of the microvilli is much greater than that of the serosal surface (15). In the present study, all measurements were standardized to an exact volume of infusion over the exact same time ( $1 \mathrm{ml}$ over $0.6 \mathrm{~min}$ via infusion pump) so that individual experiments could be compared. Because L-glucose absorption and the dilution of PEG were not different at any time after surgical bowel manipulation, the length of intestine exposed to the glucose infusion was probably constant.

The ability to perform serial measurements of intestinal absorption without the influence of surgery, anesthesia, or restraint far outweigh the inability to precisely determine intestinal length and duodenal dilution. Considering our verification studies, it is unlikely that either of the two disadvantages of the dual infusion method could affect glucose absorption by greater than the nine fold inhibition caused by surgical bowel manipulation.

This study demonstrates that surgical bowel manipulation profoundly inhibits active glucose transport. Under normal physiologic conditions, most glucose is absorbed by active transport even at high luminal concentrations. Passive absorption contributes only a small amount to total glucose transport. The low glucose absorption rates reported in previous studies are probably artifacts of surgical bowel manipulation. Even when acute models correct for the increase in the resistance of the UWL, active glucose transport will be greatly underestimated if measurements are performed within $24 \mathrm{~h}$ of surgical bowel manipulation. We speculate that measurements of other intestinal substrates that are actively absorbed may also be adversely affected by surgical bowel manipulation and anesthesia.

\section{References}

1. Uhing, M. R., and R. E. Kimura. 1995. Active transport of 3-O-methylglucose by the small intestine in chronically catheterized rats. J. Clin. Invest. 95:2799-2805.

2. Debnam, E. S., and R. J. Levin. 1975. An experimental method of identifying and quantifying the active transfer electrogenic component from the diffusive component during sugar absorption measured in vivo. J. Physiol. 246:181196.

3. Murakami, E., M. Saito, and M. Suda. 1977. Contribution of diffusive pathway in intestinal absorption of glucose in rat under normal fedding condition. Specialia. 15:1469-1470.

4. Westergaard, H. 1989. Insulin modulates rat intestinal glucose transport: effect of hypoinsulinemia and hyperinsulinemia. Am. J. Physiol. 256:G911-G918.
5. Cheeseman, C. I., and B. Harley. 1991. Adaptation of glucose transport across rat enterocyte basolateral membrane in response to altered dietary carbohydrate intake. J. Physiol. (Lond.). 437:563-75.

6. Wilson, T. H., and B. R. Landau. 1960. Specificity of sugar transport by the intestine of the hamster. Am. J. Physiol. 198:99-102.

7. Fedorak, R. N., A. B. R. Thomson, and V. M. Porter. 1991. Adaptation of intestinal glucose transport in rats with diabetes mellitus occurs independent of hyperphagia. Can. J. Physiol. Pharmacol. 69:1143-1148.

8. Meddings, J. B., and H. Westergaard. 1989. Intestinal glucose transport using perfused rat jejunum in vivo: model analysis and derivation of corrected kinetic constants. Clin. Sci. 76:403-413.

9. Boyd, C. A. R., and D. S. Parsons. 1979. Movements of monsaccharides between blood and tissues of vascularly perfused small intestine. J. Physiol. 287:271-291.

10. Thomson, A. B. R., C. A. Hotke, and W. M. Weinstein. 1982. Comparison of kinetic constants of hexose uptake in four animal species and man. Comp. Biochem. Physiol. 72A:225-236.

11. Boyd, C. A. R., and D. S. Parsons. 1978. Effects of vascular perfusion on the accumulation, distribution and transfer of 3-O-methyl-D-glucose within and across the small intestine. J. Physiol. 274:17-36.

12. Csaky, T. Z., and M. Thale. 1960. Effect of ionic environment on intestinal sugar transport. J. Physiol. Lond. 151:59-65.

13. Atisook, K., S. Carlson, and J. L. Madara. 1990. Effects of phlorizin and sodium on glucose-elicited alterations of cell junctions in intestinal epithelia. Am. J. Physiol. 258:C77-C85.

14. Madara, J. L., and J. R. Pappenheimer. 1987. Structural basis for physiological regulation of paracellular pathways in intestinal epithelia. J. Membr. Biol. 100:149-64.

15. Pappenheimer, J. R., and K. Z. Reiss. 1987. Contribution of solvent drag through intercellular junctions to absorption of nutrients by the small intestine of the rat. J. Membr. Biol. 100:123-36.

16. Westergaard, H., K. H. Holtermuller, and J. M. Dietschy. 1986. Measurement of resistance of barriers to solute transport in vivo in rat jejunum. Am. J. Physiol. 250:G727-G735.

17. Buddington, R. K., and J. Diamond. 1992. Ontogenic development of nutrient transporters in cat intestine. Am. J. Physiol. 263:G605-G616.

18. Karasov, W. H., and E. S. Debnam. 1987. Rapid adaptation of intestinal glucose transport: a brush-border or basolateral phenomenon? Am. J. Physiol. 253:G54-G61.

19. Kimura, R. E., G. Thulin, and J. B. Warshaw. 1984. The effect of ketone bodies and fatty acid on intestinal glucose metabolism during development. Pediatr. Res. 18:575-579.

20. Radziuk, J., and D. C. Bondy. 1982. Abnormal oral glucose tolerance and glucose malabsorption after vagotomy and pyloroplasty. Gastroenterology. 83:1017-1025.

21. Anderson, B. W., A. S. Levine, D. G. Levitt, J. M. Kneip, and M. D. Levitt. 1988. Physiological measurement of luminal stirring in perfused rat jejunum. Am. J. Physiol. 254:G843-G848.

22. Levitt, M. D., J. K. Furne, and D. G. Levitt. 1992. Shaking of the intact rat and intestinal angulation diminish the jejunal unstirred layer. Gastroenterology. 103:1460-1466.

23. Fedorak, R. N., E. B. Chang, J. L. Madara, and M. Field. 1987. Intestinal adaptation to diabetes. Altered $\mathrm{Na}$-dependent nutrient absorption in streptozocintreated chronically diabetic rats. J. Clin. Invest. 79:1571-1578.

24. Kimura, R. E., T. R. LaPine, and W. M. Gooch III. 1988. Portal venous and aortic glucose and lactate changes in a chronically catheterized rat. Pediatr. Res. 23:235-240.

25. Singh, G., K. I. Chaudry, L. C. Chudler, P. J. O'Neill, and I. H. Chaudry. 1991. Measurement of D-xylose gut absorptive capacity in conscious rats. Am. J. Physiol. 261:R1313-R1320.

26. Fine, K. D., A. C. Santa, J. L. Porter, and J. S. Fordtran. 1993. Effect of D-glucose on intestinal permeability and its passive absorption in human small intestine in vivo. Gastroenterology. 105:1117-1125.

27. Sparso, B. H., M. Luke, and E. Wium. 1984. Electrogenic transport of glucose in the normal upper duodenum. II. Unstirred water layer and estimation of real transport constants. Scand. J. Gastroenterol. 19:568-574.

28. Malo, C., and A. Berteloot. 1991. Analysis of kinetic data in transport studies: new insights from kinetic studies of $\mathrm{Na}(+)$-D-glucose cotransport in human intestinal brush-border membrane vesicles using a fast sampling, rapid filtration apparatus. J. Membr. Biol. 122:127-41.

29. Meddings, J. B., D. DeSouza, M. Goel, and S. Thiesen. 1990. Glucose transport and microvillus membrane physical properties along the crypt-villus axis of the rabbit. J. Clin. Invest. 85:1099-1107.

30. Moe, A. J., and M. J. Jackson. 1987. Isolation and characterization of brush border membrane vesicles from pig small intestine. Comp. Biochem. Physiol. A. 88:511-517.

31. Debnam, E. S., W. H. Karasov, and C. S. Thompson. 1988. Nutrient 
uptake by rat enterocytes during diabetes mellitus; evidence for an increased sodium electrochemical gradient. J. Physiol. Lond. 397:503-512.

32. Levitt, M. D., J. K. Furne, A. Strocchi, B. W. Anderson, and D. G. Levitt. 1990. Physiological measurements of luminal stirring in the dog and human small bowel. J. Clin. Invest. 86:1540-1547.

33. Colombato, L. A., C. Sabba, J. Polio, and R. J. Groszmann. 1991. Influence of anesthesia, postanesthetic state, and restraint on superior mesenteric arterial flow in normal rats. Am. J. Physiol. 260:G1-G6.

34. Gumbleton, M., P. J. Nicholls and G. Taylor. 1990. Differential influence of laboratory anaesthetic regimens upon renal and hepatosplanchnic haemodynamics in the rat. J. Pharm. Pharmacol. 42:693-697.

35. Winne, D. 1979. Influence of blood flow on intestinal absorption of drugs and nutrients. Pharmac. Ther. 6:333-393.

36. Nicholls, T. J., H. J. Leese, and J. R. Bronk. 1983. Transport and metabolism of glucose by rat small intestine. Biochem. J. 212:183-187.

37. Rich-Denson, C. a. K., R. E. 1988. In vivo evidence that most of the intraluminally absorbed glucose is absorbed intact into the portal vein and not metabolized to lactate. Biochem. J. 254:931-934.

38. Hakim, A. A., and N. Lifson. 1969. Effects of pressure on water and solute transport by dog intestinal mucosa in vitro. Am. J. Physiol. 216:276-284.
39. Harris, M. S., and J. G. Kennedy. 1988. Relationship between distention and absorption in rat intestine. II. Effects of volume and flow rate on transport. Gastroenterology. 94:1172-1179.

40. Karbach, U., and R. Wanitschke. 1984. Influence of serosal hydrostatic pressure on net water and electrolyte transport across the isolated rat colonic mucosa exposed to different secretagogues. Naunyn-Schmiedeberg's Arch. Pharmacol. 327:336-341.

41. Lee, J. S. 1984. Intraluminal distension pressure on intestinal lymph flow, serosal transudation and fluid transport in the rat. J. Physiol. (Lond.). 355:399409.

42. Harris, M. S., K. Ramaswamy, and J. G. Kennedy. 1989. Induction of neurally mediated $\mathrm{NaHCO} 3$ secretion by luminal distension in rat ileum. Am. J. Physiol. 257:G191-G197.

43. Hollander, D., S. Koyama, V. Dadufalza, D. Q. Tran, P. Krugliak, T. Ma, and K. Y. Ling. 1989. Polyethylene glycol 900 permeability of rat intestinal and colonic segments in vivo and brush border membrane vesicles in vitro. J. Lab. Clin. Med. 113:505-515.

44. Biolo, G., P. Tessari, S. Inchiostro, D. Bruttomesso, C. Fongher, L. Sabadin, M. G. Fratton, A. Valerio, and A. Tiengo. 1992. Leucine and phenylalanine kinetics during mixed meal ingestion: a multiple tracer approach. Am. J. Physiol. 262:E455-E465. 